\title{
Distribution of slushflows in northern Europe and their potential change due to global warming
}

\author{
T. Sidorova, ${ }^{*}$ N. Belaya, V. Perov \\ Laboratory of Snow Avalanches and Mudflows, Department of Geography, Moscow State University, 119899 Moscow, Russia
}

\begin{abstract}
The distribution of slushflows in northern Europe is described. Schematic maps of the beginning and ending periods of slushflow risk are presented. The months with maximum slushflow activity are also shown. Potential changes in the geographic and temporal distribution of slushflows due to global warming were analyzed for this region. Calculations for the year 2050 were done on the basis of climatic changes given by three global circulation models. The method of calculation was based on the general relationships between climatic parameters and the geographical and temporal distribution of slushflows. Schematic maps of potential distribution of slushflows show changes when calculated according to the most extreme of the three climatic-change scenarios.
\end{abstract}

\section{INTRODUGTION}

In describing the geographic and temporal distribution of slushflows in northern Europe we consider the Scandinavian Peninsula; the Kola Peninsula, northwest Russia; the British Isles; and Iceland. The description of the temporal distribution includes the dates of the beginning, ending and duration of the periods of slushflow risk and the months of maximum slushflow activity. The geographic boundaries of slushflow distribution were taken from the preliminary version of the "Map of the world mudflow phenomena", scale 1:15000 000 (Perov and others, 1997). Work on this project is continuing in the Laboratory of Snow Avalanches and Mudflows, Moscow State University, under the leadership of V. F. Perov.

We also analyzed potential changes in the geographic and temporal distribution of slushflows due to global warming for these regions. Calculations for the year 2050 were made on the basis of climate-change scenarios given by three global circulation models (GCMs): the Geophysical Fluid Dynamic Laboratory model (GFDL), the United Kingdom Meteorological Office model (UKTR) and the Max Planck Institute for Meteorology model (MPI).

The method of calculation was based on the general relationships between climatic parameters and the geographical and temporal distribution of slushflows described by Sidorova $(1997,1998)$, with some later improvements.

\section{DATA AND METHODS}

The modern geographic and temporal distribution of slushflows was calculated on the basis of an analysis of natural factors affecting slushflow formation and compiled actual reports of slushflow events (Rapp, 1960; Hestnes and Sandersen, 1987; Perov, 1989; Hestnes and Bakkehoi, 1995; Chernouss and others, 1998; Rapp and others, 1998).

\footnotetext{
* Present address: 3528 Slopeview Drive, San Jose, CA 95148, U.S.A.
}

The main features of the calculation method are the following. The formation of slushflows is considered to be a normal phenomenon in cold regions where the sum of daily temperatures, during the period with average daily temperatures of $>10^{\circ} \mathrm{C}$, is $<1000^{\circ} \mathrm{C}$. This works for most types of climate, but for the oceanic climate type the limit is higher, $1500^{\circ} \mathrm{C}$. In the Scandinavian mountains the climatic boundary is located on the main watershed ridge. The beginning of the period of slushflow risk is the month of the first stable snow cover for regions with oceanic climate type, and the last month of the cold period for other regions.

The end of the period of slushflow risk is the last month of snow cover. Maximum slushflow activity occurs during the first 2 months of the warm period in most of the regions considered, but during the autumn-winter months on the Norwegian coast (Hestnes and Sandersen, 1998).

The same relationships - (a) the prolongation of the slushflow risk period and the prolongation of the period with snow cover and the cold period, and (b) the distribution of slushflows in space and the temperature characteristics of regional warm periods - were used to estimate potential changes in the geographical and temporal distribution of slushflows.

Data on modern climate and snow cover were taken from the International Institute of Applied Systems Analysis (IIASA) dataset (Leemans and Cramer, 1991) with a regular grid of points on a scale $0.5^{\circ}$ and from maps in the World atlas of snow and ice resources (Kotlyakov, 1997).

The Finnish Research Program on Climate Change (SILMU) (Carter and Tuomenvirta, 1995) was used to estimate potential changes in the geographic and temporal distribution of slushflows. SILMU climate scenarios derived from simulations with three coupled ocean-atmosphere GCMs: GFDL 1991, UKTR 1994 and MPI 1992. Rates of change vary in time, are monthly in resolution and are interpolated to local scale. All three scenarios are based on central estimates of climate sensitivity $2.5^{\circ} \mathrm{C}$. This program provides data about changes in the average monthly air temperature and precipitation for any year up to 2050 in comparison with 


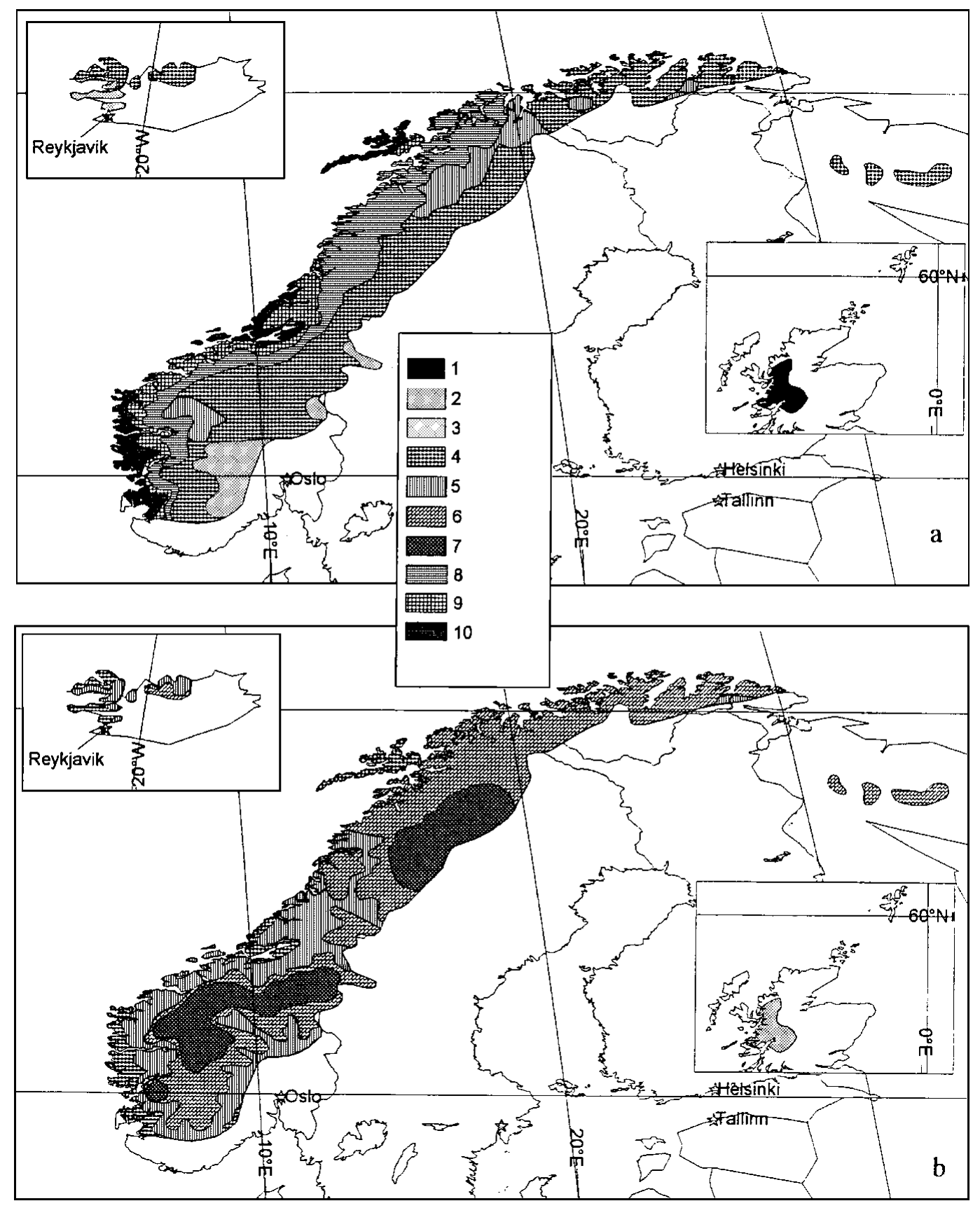

Fig. 1. The times of the beginning $(a)$ and ending $(b)$ of periods of modern slushflow risk in Scandinavian Peninsula, Kola Peninsula, Iceland (left insert) and Scotland (right insert): 1. January, 2. February, 3. March, 4. April, 5. May, 6. Fune, 7. July, 8. October, 9. November, 10. December.

modern levels based on 1990. These data are available in table form in a regular $1^{\circ}$ grid for the Scandinavian Peninsula and on a scale of $2-3^{\circ}$ in map form for other regions. Potential changes in the duration of period with snow cover were evaluated using a method published in Kotlyakov (1997). This method is based on the fact that the length of the period of snow cover is dependent upon the length of the cold period and on the total quantity of solid precipitation.

The main differences in the intensity of global warming between the three GCMs considered can be seen from a comparison of the changes in mean annual characteristics. UKTR forecasts the most dynamic climatic changes. According to this model, mean annual air temperature will increase approximately $2.5-3.0^{\circ} \mathrm{C}$ in most parts of the Scandinavian Peninsula, $1.5^{-}-2.5^{\circ} \mathrm{C}$ in Scotland and $0.5^{-}-1.0^{\circ} \mathrm{C}$ in Iceland. GFDL forecasts an increase of $1.0-1.5^{\circ} \mathrm{C}$ in the mean annual air temperature in most Scandinavian regions and in Scotland, and an increase of $1.5-2.0^{\circ} \mathrm{C}$ in Iceland. MPI forecasts even less significant warming. In Iceland and Scotland the warming is $0.5-1.0^{\circ} \mathrm{C}$, and in other areas it is around $1.0-1.5^{\circ} \mathrm{C}$. The largest increase in annual precipitation (up to $20 \%$ in northern Scandinavia and in Scotland), usually in winter, is also forecast by UKTR. GFDL forecasts an increase in the annual precipitation by $10 \%$, generally in the autumn and summer months. MPI forecasts some decrease in precipitation because of a decrease in spring precipitation almost everywhere and in summer precipitation in some significant regions.

\section{THE MODERN GEOGRAPHIC AND TEMPORAL DISTRIBUTION OF SLUSHFLOWS}

Schematic maps of the times of the beginning and ending of periods of modern slushflows risk are shown in Figure 1. These 


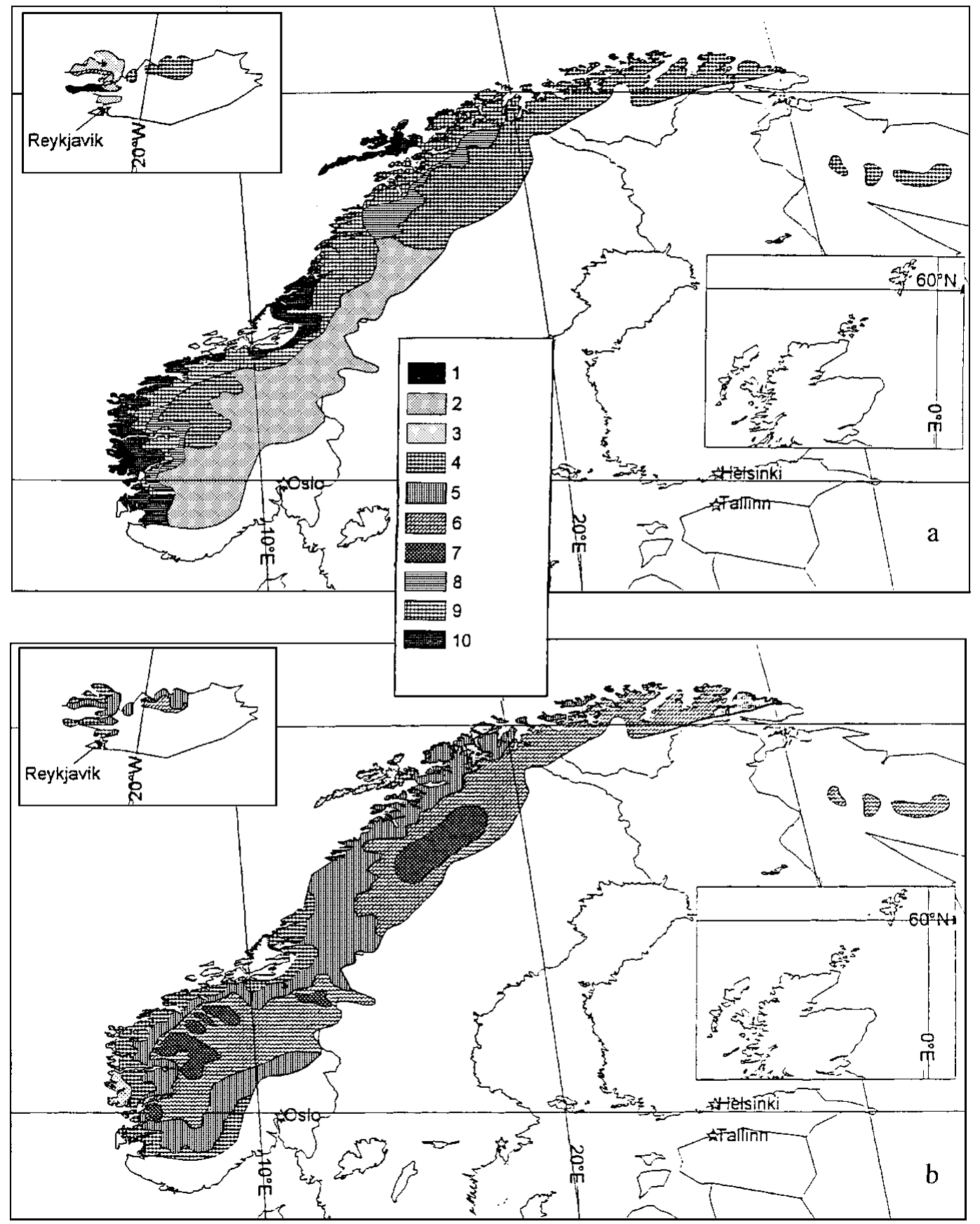

Fig. 2. The potential times of the beginning ( a) and ending ( $b$ ) of periods of slushflow risk for the year 2050 in Scandinavian Peninsula, Kola Peninsula, Iceland (left insert) and Scotland (right insert): 1. January, 2. February, 3. March, 4. April, 5. May, 6. June, 7. July, 8. October, 9. November, 10. December.

maps were produced on the basis of modern data about climate and snow cover using the calculation method described above. Slushflows are ordinary natural phenomena in all mountain regions of Scandinavia, the Kola Peninsula and Iceland. Slushflows are also possible in the highest mountain ranges of Scotland (Onesti and Hestnes, 1989). In other mountainous regions of the United Kingdom and of Ireland climatic conditions are not propitious for the formation of slushflows.

The duration of the period of slushflow risk ranges from 9 to 2 months in these regions. It is 9 months (OctoberJune) on the northwest coast of Norway from the Polar Circle to $70^{\circ} \mathrm{N}$. The warming effect of the North Atlantic current together with variations in altitude and latitude strongly influences the duration of the risk period. The duration of the slushflow risk period usually decreases to the south along the coast and increases with elevation on the western slopes of Scandinavian mountains. In all regions with cold, stable winters, such as the east slopes of the Scandinavian mountains, the north coast of Norway, Iceland and the mountains of the Kola Peninsula, the period of slushflow risk is only $2-3$ months. The first month of the period of slushflow risk in these locations is usually April or May, and the last month is usually May or June. According to our estimates, slushflows are possible even at the beginning of July in some of the highlands of Sweden (Fig. 1b). Maximum slushflow activity in most of the regions we have considered occurs from April to June, most typical- 
ly in May. On the coast of Norway, maximum slushflow activity occurs in winter. On the northwest coast it occurs also in later autumn. In Scotland it is also in winter.

By describing the modern geographic and temporal distribution of slushflows in northern Europe, the authors do not propose to describe something absolutely new and unknown to our colleagues from these regions. We want only to present a possible "office" method of estimating the geographic and temporal distribution of slushflows on a gross scale on the basis of standard climatic information. This method theoretically can be used for any region, including little-known regions, where it could be more useful. Using this method, it is possible to estimate potential changes in the geographic and temporal distribution of slushflows given any scenario of climatic change.

\section{POTENTIAL GHANGES OF GEOGRAPHIG AND TEMPORAL DISTRIBUTION OF SLUSHFLOWS}

Potential changes to the beginning and the ending times of slushflow risk for the year 2050 are shown in Figure 2. These estimates were made on the basis of the most dynamic scenario of climatic change, the UKTR model. According to these estimates, slushflows will cease as typical natural phenomena in Scotland and will become improbable on the coast of Trondheim Fjord, Norway. The duration of the period of slushflow risk will decrease by $1-2$ months (sometimes even by 3 months) in the coastal regions and will not change in most other areas. The first month of slushflow risk will generally be 1 month later in coastal regions and 1 month earlier in inland regions. The last month of slushflow risk and the period with maximum slushflow activity will be 1 month earlier almost everywhere.

According to estimates based on the GFDL model, it is possible to anticipate the disappearance of slushflows only in Scotland. All other possible changes are the same as described above. According to estimates based on the MPI model, there will be no significant changes in the geographic distribution of slushflows through the year 2050 in these regions. Slushflows can cease only locally at their outer boundary.

\section{CONGLUSION}

The main features of the modern geographic and temporal distribution of slushflows in northern Europe are the following:

1. Slushflows are widespread in all mountainous regions of Scandinavia, the Kola Peninsula and Iceland. Slushflows are also possible in the highest mountain ranges of Scotland.

2. The duration of slushflow risk ranges from 9 to 2 months in these regions. It is 9 months on the northwest coast of Norway. It decreases to the south along the coast to 45 months. In the inland regions of the Scandinavian and Kola Peninsulas it is usually $2-3$ months.

3. The month with maximum slushflow activity in most of these regions is May. On the coast of Norway and in Scotland, however, the maximum activity occurs during the winter months.

4. The first schematic maps of the temporal distribution of slushflows have been produced for these regions.
Estimates of potential changes in the distribution of slushflows in northern Europe up to the middle of the 21st century show the following:

1. The total area affected by slushflows will decrease only slightly, even according to the most dynamic scenario of climatic change, the UKTR model. Slushflows will cease as typical natural phenomena in Scotland and on the coast of the Trondheim Fjord.

2. The duration of slushflow risk will decrease to $1-2$ months in coastal regions and will not change in most other areas, according to all three considered scenarios of climatic change.

3. Maximum slushflow activity will be 1 month earlier in most considered regions according to the UKTR and GFDL scenarios.

4. According to the most conservative scenario of climatic change, the MPI model, there will be no significant changes in the geographic distribution of slushflows.

\section{REFERENGES}

Carter, T. and H. Tuomenvirta. 1995. SILMUSCEN scenarios of changes in climate, $\mathrm{CO}_{2}$ concentration and sea level over Finland and the Nordic region: 1990-2100. Version 1.0 February 1995. Helsinki, Finnish Meteorological Institute.

Chernouss, P., O. Tyapkina, E. Hestnes and S. Bakkehøi. 1998. The differentiation of thaws in connection with slushflow occurrences. In Hestnes, E., ed. 25 Years of Snow Avalanche Research, Voss 12-16 May 1998. Proceedings. Oslo, Norwegian Geotechnical Institute, 89-94. (NGI Publication 203.)

Hestnes, E. and S. Bakkehøi. 1995. "Prediction of slushflow hazard". Objectives and procedures of an ongoing research project in Rana, north Norway. In Sivardière, F., ed. Les apports de la recherche scientifique à la sécurité neige, glace et avalanche. Actes de Colloque, Chamonix 30 mai-3 juin 1995. Grenoble, Association Nationale pour l'Étude de la Neige et des Avalanches (ANENA), 335-340.

Hestnes, E. and F. Sandersen. 1987. Slushflow activity in the Rana district, north Norway. International Association of Hydrological Sciences Publication 162 (Symposium at Davos 1986 - Avalanche Formation, Movement and Effects), 317-329.

Hestnes, E. and F. Sandersen. 1998. Slushflow hazard control. A review of mitigative measures. In Hestnes, E., ed. 25 Tears of Snow Avalanche Research, Voss 12-16 May 1998. Proceedings. Oslo, Norwegian Geotechnical Institute, 140-147. (NGI Publication 203.)

Kotlyakov, V. M., ed. 1997. Atlas snezhno-ledovykh resursa mira [World atlas of snow and ice resources]. Moscow, Russian Academy of Sciences. Institute of Geography.

Leemans, R. and W. P. Cramer. 1991. The IIASA database for mean monthly values of temperature, precipitation and cloudiness on a global terrestrial grid. Laxenburg, International Institute for Applied Systems Analysis. (Research Report RR-91-18.)

Onesti, L. J. and E. Hestnes. 1989. Slush-flow questionnaire. Ann. Glaciol., 13, 226-230.

Perov, V. F. 1989. Selevye yavleniya na territorii SSSR [Mudflow phenomena in the territory of the USSR]. Itogi Nauki Tekh., Ser. Gidrologiya Sushi 16.

Perov, V., I. Artyukhova, O. Budarina, T. Glazovskaya and T. Sidorova. 1997. Map of the world mudflow phenomena. In Chen, C., ed. Debris-flow hazards mitigation: mechanics, prediction, and assessment. New York, American Society of Civil Engineers, 322-331.

Rapp, A. 1960. Recent development of mountain slopes in Kärkevagge and surroundings, northern Scandinavia. Geogr. Ann., 42(2-3), 65-200.

Rapp, A., M. Gude and D. Scherer. 1998. Snowmelt and slush avalanches/slushflows in northern mountains, Sweden. A video presentation. In Hestnes, E., ed. 25 Years of Snow Avalanche Research, Voss 12-16 May 1998. Proceedings. Oslo, Norwegian Geotechnical Institute, 220. (NGI Publication 203.)

Sidorova, T. L. 1997. Potential changes of mudflow phenomena due to the global warming. In Chen, C., ed. Debris-flow hazards mitigation: mechanics, prediction, and assessment. New York, American Society of Civil Engineers, 540-549.

Sidorova, T. 1998. Regime of mudflows and its potential changes due to global warming. In Hestnes, E., ed. 25 Years of Snow Avalanche Research, Voss 12-16 May 1998. Proceedings. Oslo, Norwegian Geotechnical Institute, 249-253. (NGI Publication 203.) 